\title{
CHRONIC RHEUMATIC DISEASES FROM THE SERVICES IN E.M.S. HOSPITALS
}

BY

\section{W. BUCKLEY}

This survey of chronic rheumatic diseases in the Services is limited to cases which have been deemed suitable for treatment by physiotherapy in certain spa hospitals under the Emergency Medical Service of the Ministry of Health. The selection of cases depended largely on the views of the medical and surgical staffs of the Service hospitals and depots at which the cases were first received for treatment. It follows that many cases were received from some, and few or none from others. While the selection depended in some degree upon the availability of physiotherapeutic treatment in the various military hospitals, it was also affected by the extent of the experience of rheumatic diseases and the most effective methods of treatment possessed by the medical officers and the Medical Boards concerned. Unfortunately patients were often detained in general hospitals, and there for many weeks underwent treatment by heat and massage. Many such patients would have recovered more quickly in a hospital specially equipped for physiotherapy, where they would not have been confined to bed, and where systematic exercises adapted to the case would have been a feature of the treatment. These factors make it impossible in any way to correlate the numbers treated with the numbers at risk.

Patients came from all branches of the Forces and were treated in two hospitals, one being reserved for officers and the other for N.C.O.s and privates. Cases were also received from the W.R.N.S., the A.T.S., and the W.A.A.F., and from the nursing services. Cases received for treatment at the two hospitals from the beginning of 1940 to the end of 1945 numbered 1,497, of whom 226 were commissioned officers, and the remainder other ranks ; 52 were from the women's Services. During the latter half of the time, half the beds previously reserved for rheumatic cases were taken over for the treatment of peripheral nerve injuries by reason of the facilities available for their physiotherapeutic treatment. These cases are not taken into account in this survey.

\section{Diseases Treated: Causes and Contributory Factors}

A certain disparity is to be noted which is largely attributable to the fact that the cases among other ranks were under the care of different medical officers, whose views on diagnosis and nomenclature were not always the same.

Fibrositis-a somewhat loose designation, including conditions differing both in aetiology and pathology and having in common only the symptoms of pain and stiffness and the localization of the trouble in the fibrous tissues-accounted for the largest proportion of the cases which were sent for treatment.

Classification of admissions: percentage

\begin{tabular}{|c|c|c|c|c|}
\hline \multirow{2}{*}{\multicolumn{2}{|c|}{ Subacute rheumatism }} & & \multirow{2}{*}{$\begin{array}{c}\text { Officers } \\
4\end{array}$} & \multirow{2}{*}{$\begin{array}{c}\text { Other ranks } \\
4 \cdot 5\end{array}$} \\
\hline & & . & & \\
\hline Fibrositis & .. & .. & 35 & $52 \cdot 5$ \\
\hline Lumbago & .. & .. & - & $4 \cdot 5$ \\
\hline Sciatica & & .. & 15 & $12 \cdot 3$ \\
\hline Rheumatoid ar & rthritis & . & 19 & 19 \\
\hline Osteo-arthritis & $\ldots$ & .. & 6 & $1 \cdot 3$ \\
\hline Spondylitis & $\ldots$ & .. & 9 & $1 \cdot 1$ \\
\hline Synovitis & . & .. & - & $2 \cdot 0$ \\
\hline Pes planus & $\ldots$ & .. & - & $1 \cdot 5$ \\
\hline Gout & $\ldots$ & .. & 5 & 0.4 \\
\hline Other diseases & .. & . & 7 & 0.9 \\
\hline
\end{tabular}

The results of treatment were affected in some measure by the fact that, among the "other ranks" more particularly, there were two categories which tended to reduce the general average of recovery: (1) men from the reserve, many of whom had served in the last war and were at an age when their capacity to stand up to prolonged physical strain was deficient; and (2) a fairly large number who had been passed by recruiting boards but who, from various causes, had broken down in training. Some of the latter had "gone sick" within a week or two of being called up, and others had been in and out of hospital for months-in a few cases for more than a year-generally with very indefinite complaints. The truth of the saying that malingering is rare but exaggeration is common was frequently illustrated, and it cannot be denied that the disease which was once described by an eminent surgeon as miles antiquis was not unknown. A good many cases of these types were sent for outpatient treatment from a depot of Pioneers in the neighbourhood. They were mainly men of low category, and complained of stiff and painful backs and shoulders, flat feet, etc. Often they had histories of old injuries in civil life, though they had little or nothing in the way of objective evidence to explain their symptoms. These were very unsatisfactory cases to treat. It appeared likely that some were psychosomatic or psychoneurotic in nature, but a psychiatrist was not available to investigate them from this standpoint.

It was perhaps inevitable that the tendency of recruiting boards to treat chronic backache as a merely neurotic, or as a shirker's, complaint, led 
to many men being taken into the Services who were a liability from the first. Cases with a clear history of serious accident to the back in previous years were met with, and also a few cases of wellmarked adolescent kyphosis. Complaints of pain in the lumbar and sacral regions frequently presented a difficult problem in diagnosis; on clinical examination there might be no objective evidence beyond, perhaps, some limitation of forward bending or a flattening of the normal lumbar curvature, possibly with spasm of the erector spinae which, without eliciting pain, could be corrected with the patient in the supine posture. In such cases it was difficult to be sure that the trouble was not one of defective posture, and that physical training-so far from being inadvisable-might not prove of permanent benefit to the recruit.

In the majority of cases of fibrositis sent to these hospitals the cause appeared to be physical strain, or exposure, or a combination of both. In a smaller number there was a history of some infection, though the causal relation was not always clear. A great variety of infections were noted, the most common being a history of an attack of subacute rheumatism, tonsillitis, otitis media, and dysentery; among the others might be noted chronic appendicitis, colon bacilluria, amoebiasis and nonspecific urethritis. In some cases with a history of strain, $x$-ray examination revealed congenital defects, most commonly sacralization of the fifth lumbar vertebra. This latter defect appears to be a common predisposing factor in strainespecially unilateral strain; but in view of the frequency with which this abnormality is met with in radiography of the vertebral column undertaken for other purposes, its relationship cannot be regarded as certain.

Periarthritis of the shoulder-often called brachial neuritis-has been included with fibrositis and was usually associated with strain.

Cases of the psychoneurotic or psychosomatic type described by Halliday and by R. G. Gordon were met with, but were not numerous. As no psychiatrist was available, the ordinary physical methods of treatment were used, with good results in the milder cases. A psychological element leading to exaggeration of symptoms-specially in cases where long-continued strain and exposure had reduced the morale and general powers of resistance-might often be present, but was usually amenable to treatment and rest.

Heavy lifting, starting up heavy motors from cold, and similar efforts were clearly the exciting cause in many instances. Strain from lifting appeared to be the most common cause of lumbar fibrositis in the nursing services. The rigid and flattened spine which is common in these cases led sometimes to the patient arriving with a diagnosis of ankylosing spondylitis.

Fibrositis due to exposure can usually be effectively treated by heat and massage, which are available in most of the military hospitals. Only the more obstinate cases, in which there was commonly some other aetiological factor, were transferred to physiotherapy centres. Thus no statistical conclusions about the relative proportion of the different aetiological factors can be drawn from the cases treated in these hospitals. The researches of Copeman and Ackerman (Quart. J. Med., 194, 13, 37) and of Mylechreest (this Journal, 1944-5, 4,77 ) have thrown a good deal of light on a difficult subject, and it is likely that many cases which would otherwise have been sent to the special centres for physiotherapy were, in consequence, treated in military hospitals by the methods of these authors. The fact may thus be explained that exposure was less often than in the last war alleged to be the cause of fibrositis and other rheumatic conditions, and that strain was more frequently deemed responsible. Changed conditions of warfare furnish a further explanation. The absence of trench life and the enormous increase in mechanical transport had their effect; conditions incidental to tank warfare were often blamed for myalgic disorders. In the Army, sleeping on wet ground, and, in the Navy, long immersion after being wrecked, although of frequent occurrence, seem rarely to have given rise to serious rheumatism of chronic type.

It seems probable that troops serving abroad were in much harder training and were better fitted to stand exposure in the later stages of this war than in 1914-18. The impression was formed that there were more cases of fibrositis among men training in this country who had never been abroad than in those returning from foreign service; but this observation remains to be tested later, when records are complete.

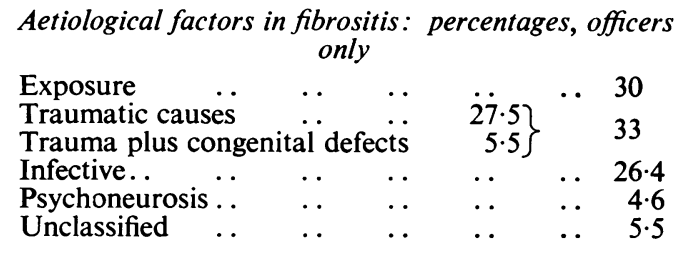

\section{Sciatica}

There were many cases of sciatic pain; and, of these, $30 \%$ showed definite evidence of prolapse of an intervertebral disc. In about an equal number there were grounds for suspecting that this might be the case. Of the remainder, the majority were due to fibrositis of the lumbo-sacral ligaments and gluteal muscles, and in about one-third of these $x$ rays showed the presence of some congenital abnormality, as described in the section dealing with fibrositis. The cases in which there were indications of a disc lesion were transferred to orthopaedic or neurological centres. The remainder were generally effectively treated by physiotherapy; the methods will be described later. It is probable that many cases due to a prolapsed disc were recognized in the general hospitals and transferred to special hospitals directly, so that the percentages given above may be too low. 
Subacute Rheumatism and Rheumatoid Arthritis

A small number of cases were admitted for treatment of stiffness of joints following subacute rheumatism; there were in addition a few cases with a history of pain and swelling in the joints, the pain moving from one joint to another over a period of several weeks or months. There would be a history of moderate fever at the onset, and an accelerated sedimentation rate. Salicylates had little effect beyond relieving pain. In several cases sulphonamides had been given-also without benefit-while the patients were in general hospitals. There would be remissions and recurrences with the same symptoms, and the condition would gradually become chronic, settling in the proximal phalangeal joints, in the wrists, and sometimes in the knees or other joints-presenting the picture of a true rheumatoid arthritis. At this stage the sedimentation rate had generally become normal, and the joints, though thickened, showed no sign of breaking down or of ankylosis; though from contraction of the capsular ligaments there was generally some restriction of movement, as in closing the fist. Otherwise, recovery tended to be complete, and so far as could be traced no further development occurred. While such cases might be regarded as true rheumatoid arthritis, they were clinically different from the usual type; there was no cardiac involvement in most cases. The writer met with similar cases in civil hospital practice before the war-chiefly in young male adultsand Professor Noah Morris recently stated in a personal communication that he had met with several cases of the same type and had come also to the conclusion that they represented a link between rheumatic fever and rheumatoid arthritis; no infective foci were identified.

There were many cases of rheumatoid arthritis of the more common kind. These usually made good progress, and many returned to duty-though in a lower category. Gonorrhoeal arthritis was rarely seen, probably because it was recognized and treated in special hospitals. In a few cases there was a history of gonorrhoeal infection some years earlier, but the arthritis was probably not gonococcal. In two cases there was a history of non-specific urethritis. Dysenteric arthritis was less common than in the 1914-18 war. In several cases there was a history of malaria, but it did not appear to have any direct association with the arthritis. Vaccines were not used, and gold only in a few cases of the more severe type. The effect of rest in favourable conditions, and of physiotherapy, were in many cases sufficient.

\section{Spondylitis}

The incidence of ankylosing spondylitis showed a marked increase compared with civilian practice before the war. It was not usually of the adolescent type so far as age of incidence was concerned, and probably for this reason was less acute and rapidly progressive. There were no cases in women.
There was frequently a history of jarring of the spine, but since this must have been a very frequent experience in war conditions, without any after effect, its aetiological significance is doubtful. $X$ rays generally showed the greatest degree of bony change to be in the lowest dorsal and upper lumbar vertebrae. The sacro-iliac joints were affected, but to a less pronounced degree than in the more acute form of adolescence; and osteoporosis was less marked. The figures available for age incidence among the "other ranks" are incomplete, but the following from the records of cases among officers serve to indicate the general age incidence:

\begin{tabular}{c|c|c|c|c}
\hline \multirow{2}{*}{$\begin{array}{c}\text { Total number of } \\
\text { cases among officers }\end{array}$} & \multicolumn{4}{|c}{ Age at onset } \\
\cline { 2 - 5 } 226 & $20-25$ & $25-30$ & $30-35$ & $\begin{array}{c}35 \text { and } \\
\text { above }\end{array}$ \\
\cline { 2 - 5 } & 9 & 4 & 5 & 2 \\
\hline
\end{tabular}

In the later stages of the war many cases were sent for physiotherapy after a course of deep $x$-ray treatment, and these did well. Many cases recovered sufficiently to remain in the Services in a lower category.

\section{Osteo-Arthritis}

Among the older men osteo-arthritis as a late effect of chronic strains, synovitis, and fibrositis of the ligaments-especially of the spine-was a frequent cause of disability requiring physical treatment. The presence of small osteophytes of the vertebrae detected in $x$-ray examination in men complaining of painful backs appeared frequently to have been regarded as pathological and a form of spondylitis. The fact that such a condition may almost be regarded as a normal occurrence in men of middle age who have followed occupations demanding much muscular effort appeared to be generally unknown. The symptoms complained of in such cases probably had no relation to the $x$-ray appearances, and were due to strain and fibrositis. Treatment by the usual physiotherapeutic methods led generally to recovery and return to duty, but in some cases, where the patient had become aware of the results of the $x$-ray examination, he tended to regard himself as permanently disabled and to behave accordingly.

\section{Gout}

Gout accounted for a small percentage of the total admissions, and appeared to be relatively more common in the Navy than in the other Forces. It presented no unusual characteristics, and complete recovery was the rule.

\section{Other Diseases}

Among the other conditions treated, sacro-iliac and lumbo-sacral strain, chronic synovitis, flat foot, and metatarsalgia were the most common, and 
do not call for any special description. They formed only a small proportion of the whole number.

\section{Methods of Treatment}

As a routine measure in all suitable cases, warm immersion baths with hot underwater douching were used for the treatment of painful and stiffened joints and stiffness due to fibrositis. These were preceded in some cases by general vapour baths, and in a large proportion by the application of hot peat packs to the affected joints. A development of the simple immersion bath was the deep pool, in which an operator accompanied the patient into a large pool bath of warm water, and carried out passive movements with local hot douching, encouraging such active movements as the patient was capable of, and which were more easily carried out when the limbs were supported by water. This method was especially useful for stiffness of the larger joints and for ankylosing spondylitis. Very crippled patients could be lowered into the baths by means of a crane. Massage under water in a shallow bath also proved an effective and popular method of treatment for chronic fibrositis, lumbago, and strain of the back. In suitable cases the treatment went on to immersion in a tepid swimming bath in which swimming and other movements could be freely practised.

Whirlpool baths were used-often alternately with the methods mentioned above-for local treatment of painful and stiffened joints, and also for disorders of the peripheral circulation, trench foot, Raynaud's disease, and chronic oedema from various causes; in these the water, at a temperature of 100 to $105^{\circ} \mathrm{F}$., was kept by mechanical means in a state of violent agitation, producing a massaging effect. General aerated baths of a similar but milder character were used at a lower temperature as a general stimulant and tonic to the peripheral circulation.

Massage was widely used, and all forms of electrotherapy, except $x$ rays, were available. The existence of a large massage school attached to the hospital provided an ample staff for these measures.

A feature of the treatment in these hospitals was systematic physical exercises adapted to the patient's condition. They were arranged in grades, beginning with mild exercises and progressing, as the patient improved, to more strenuous activities, including regular walks with an orderly, and games, both indoor and outdoor. Towards the end of the war occupational therapy was introduced on a large scale. Recreation was regarded as an essential feature of treatment. The results were good and in some cases remarkable.

My thanks are due to Major-General Sir A. G. Biggam and Sir Arthur MacNalty for permission to publish this chapter of the "Medical History of the War," also to Dr. Charles Newman, the Editor acting for the Ministry of Health, and Sir Francis Fraser, Director General of the E.M.S. hospitals for rheumatic conditions. 